\title{
False Killer Whale Dorsal Fin Disfigurements as a Possible Indicator of Long-Line Fishery Interactions in Hawaiian Waters ${ }^{1}$
}

\author{
Robin W. Baird ${ }^{2}$ and Antoinette M. Gorgone ${ }^{3}$
}

\begin{abstract}
Scarring resulting from entanglement in fishing gear can be used to examine cetacean fishery interactions. False killer whales (Pseudorca crassidens) are known to interact with the Hawai'i-based tuna and swordfish long-line fishery in offshore Hawaiian waters. We examined the rate of major dorsal fin disfigurements of false killer whales from nearshore waters around the main Hawaiian Islands to assess the likelihood that individuals around the main islands are part of the same population that interacts with the fishery. False killer whales were encountered on 11 occasions between 2000 and 2004, and 80 distinctive individuals were photographically documented. Three of these $(3.75 \%)$ had major dorsal fin disfigurements (two with the fins completely bent over and one missing the fin). Information from other research suggests that the rate of such disfigurements for our study population may be more than four times greater than for other odontocete populations. We suggest that the most likely cause of such disfigurements is interactions with longlines and that false killer whales found in nearshore waters around the main Hawaiian Islands are part of the same population that interacts with the fishery. Two of the animals documented with disfigurements had infants in close attendance and were thought to be adult females. This implies that even with such injuries, at least some females may be able to produce offspring, despite the importance of the dorsal fin in reproductive thermoregulation.
\end{abstract}

INCIDENTAL MORTALITY IN fisheries is probably the greatest conservation concern for cetaceans worldwide (Read et al. 2003). Identifying fishery interactions can be done in a variety of ways: (1) using observers on fishing vessels (e.g., Jefferson et al. 1994); (2) examination of wounds, scars, or entangled

\footnotetext{
${ }^{1}$ Field efforts were funded by the National Marine Fisheries Service, Southwest Fisheries Science Center, the Hawaiian Islands Humpback Whale National Marine Sanctuary, the M.R. \& Evelyn Hudson Foundation, the U.S. Navy (through the SWFSC), and by a donation from Tom and Chris Brayton. Research was undertaken under NMFS Scientific Research Permits No. 731-1509 and 774-1437. Manuscript accepted 12 November 2004.

${ }_{2}^{2}$ Corresponding author: Cascadia Research Collective, $218 \frac{1}{2}$ West 4th Avenue, Olympia, Washington 98501 (e-mail: rwbaird@cascadiaresearch.org or rwbaird@dal.ca).

${ }^{3}$ National Marine Fisheries Service, 101 Pivers Island Road, Beaufort, North Carolina 28516.
}

Pacific Science (2005), vol. 59, no. 4:593-601

(C) 2005 by University of Hawai'i Press

All rights reserved gear on beach-cast animals (e.g., Friedlaender et al. 2001); (3) observations of animals in the wild with entangled fishing gear (e.g., Knowlton and Kraus 2001); or (4) questionnaire surveys of fishermen (e.g., Baird et al. 2002). Each of these methods has advantages and disadvantages: (1) observer programs provide the most comprehensive and quantitative data but are expensive, particularly when fishing fleets are large; (2) only a small proportion of dead animals ever wash up on a beach, and beach-cast animals are easily damaged by scavengers, obscuring marks; (3) observations of animals in the wild with entangled fishing gear are opportunistic and likely reflect only a small proportion of animals entangled, even for large and easily observed species; and 4) questionnaire surveys often suffer from a strategic response bias, with fishermen unlikely to provide information that could result in negative management actions. Rates and patterns of entanglement-related scarring visible in photographs of animals in the wild have also been used to assess the frequency of non- 
lethal entanglements (Robbins and Mattila 2001). At least for some species, use of this technique may result in more accurate (and likely much higher) estimates of fisheries interactions than are available from examination of beach-cast animals or opportunistic observations of animals carrying fishing gear. Such studies may work well on large animals where a high proportion of individuals that interact with fishing gear break free, though applicability is questionable to smaller species, or those more difficult to approach and photograph, or those where fishing gear entanglement usually results in death.

False killer whales (Pseudorca crassidens) have been documented interacting with the Hawai'i-based tuna and swordfish long-line fishery (Nitta and Henderson 1993, Carretta et al. 2004). The estimated size of the Hawai' $i$ "stock" of false killer whales, from a line transect survey covering the entire Hawaiian Exclusive Economic Zone (EEZ), is only 268 individuals, with a coefficient of variation (CV) of 1.08 (Barlow 2003). Mobley et al. (2000) derived an estimate of 121 individuals $(\mathrm{CV}=0.47)$ based on aerial surveys within approximately $45 \mathrm{~km}$ of the main Hawaiian Islands. This stock is listed as "strategic" by the U.S. National Marine Fisheries Service (NMFS), because the estimated level of serious injury and mortality from this fishery (less than four animals per year) is greater than the Potential Biological Removal (PBR) level (approximately one animal per year) set by NMFS (Carretta et al. 2004). Most false killer whales caught in the long-line fishery are released alive but usually trailing gear and/or with apparent injuries or hooks still embedded. This fishery does not occur within approximately $80 \mathrm{~km}$ of the Hawaiian Islands but extends offshore and into international waters outside the Hawai'i EEZ, as well as into other U.S. territorial waters in the central Pacific. False killer whales in the nearshore waters of the main Hawaiian Islands are genetically distinct from animals in the eastern tropical Pacific Ocean (Chivers et al. 2003); however, the offshore range of the Hawaiian population has not yet been determined. Some or all of the fishery interactions that occur throughout the Hawaiian Islands
$\mathrm{EEZ}$, in international waters, and in other central Pacific U.S. EEZs may involve false killer whales from the Hawaiian population, but data are lacking to examine potential links. We have been photo-identifying false killer whales as part of a population assessment of this species in nearshore waters of the main Hawaiian Islands. This species is easy to approach and photograph, though scarring is difficult to document because scars heal the same color as the background body pigmentation (R.W.B., pers. obs.). In this study we use photographs of false killer whales to assess whether animals around the main islands exhibit potential signs of interactions with long-line fisheries, and we compared injury rates with those of other populations of odontocetes.

\section{MATERIALS AND METHODS}

Fieldwork occurred around all the main Hawaiian Islands from 2000 to 2004, though effort varied among islands. We used a variety of research vessels ranging in size from 6 to 18 $\mathrm{m}$ long. During 2002 and 2003 we often used two research vessels simultaneously but maintained a distance of at least several kilometers between the vessels to cover different portions of the study area. Survey speeds were generally between 16 and $30 \mathrm{~km} / \mathrm{hr}$, and two to five observers scanned 360 degrees around the boat. Search effort was concentrated in sea conditions less than Beaufort 4, off the leeward coasts of all islands. We searched nonsystematically both near shore and out to approximately $42 \mathrm{~km}$ from shore, in waters up to $4,000 \mathrm{~m}$ deep, attempting to cover as much of the study area as possible given sea conditions. All encounters with all species of odontocetes were recorded, and in the case of false killer whales, we made efforts to obtain multiple photographs of every individual in each group encountered, using Canon SLR film (2000-2002) or digital (2003-2004) cameras with $100-$ to $300-\mathrm{mm}$ zoom lenses. All photographs were examined and individuals identified based on the size and location of notches on the dorsal fin. The program Finscan (Hillman et al. 2003) was used to assist in matching individuals. Individuals were considered 
distinctive (or "marked") if the notches on the dorsal fins were large enough to be recognizable in any good-quality photograph. We classified individuals as having major dorsal fin disfigurements if they were missing the dorsal fin or if it was completely bent over at the base.

\section{RESULTS}

Between 2000 and 2004 we spent 1,684 hr searching for cetaceans, covering $23,558 \mathrm{~km}$ of trackline on 234 different vessel days (a day with two boats searching simultaneously was counted as two vessel days). Search effort was spread over 10 months of the year (all except July and August), though the total number of search days per month for all $5 \mathrm{yr}$ varied from 6 to 49. During this time we encountered 417 groups of odontocetes, representing 16 species. False killer whales were encountered on 11 occasions $(2.6 \%$ of encounters), tied for the seventh most frequently encountered species. False killer whales were documented during each of the 5 $y r$, in a total of eight different months of the year (with no obvious seasonality), off $\mathrm{O}^{\prime}$ ahu, Maui, Lāna'i, and Hawai'i. Group size ranged from 3 to 41 individuals $($ mean $=19.4$, $\mathrm{SD}=13.0$ )

We took approximately 2,500 photograph frames and documented 80 marked individual false killer whales. Of these, one is missing the dorsal fin entirely (catalog no. HIPc177 [Figure 1, top]), two have their dorsal fins bent over completely at the base (catalog nos. HIPc166 and HIPc186 [Figure 1, middle, bottom]), and a fourth has the dorsal fin partially bent over (catalog no. HIPc127). All three of these latter individuals have notches/ injuries at the base of the leading edge of the fin, and no other individuals in the catalog have notches at the base of the leading edge of the fin. For the purpose of comparisons with other populations of odontocetes, we consider only the first three individuals to have "major" dorsal fin disfigurements, thus giving a rate of major disfigurements of $3.75 \%$ of the "marked" population. The first two individuals were thought to be adult females, based on the close proximity of infants (estimated at less than a year of age) the first time they were seen. Individual HIPc177 was seen with the infant surfacing in infant position, further suggesting a mother-offspring relationship (J. Mann, pers. comm.). Photographs were obtained of both the left and right side of individual HIPc177, and from examination of photographs only a small amount of unpigmented scar tissue (estimated at $\sim 1 \mathrm{~cm}^{2}$ ) was visible at the site of the missing dorsal fin, suggesting that the wound had healed completely. The area of the missing fin was raised $\sim 1 \mathrm{~cm}$ above the dorsal surface of the whale.

\section{DISCUSSION}

Collapsed or missing dorsal fins have not previously been reported for false killer whales and have only rarely been reported for any cetaceans. Natural sources of cetacean dorsal fin injuries include both intra- (e.g., Chu and Nieukirk 1988, Visser 1998) and interspecific interactions, as from predatory sharks (e.g., Corkeron et al. 1987) or killer whales (Orcinus orca). Anthropogenic sources of such injuries include entanglements with fishing gear (e.g., Green et al. 1991, Mann et al. 1995), gunshot wounds (e.g., Bigg et al. 1987), boat strikes (e.g., Wells and Scott 1997, Visser and Fertl 2000), scarring from tags (e.g., Scott et al. 1990), and deliberate notches placed in the fin for identification purposes (e.g., Bigg 1982). In extreme cases individuals of some species have been documented with bentover or missing dorsal fins. Bent-over dorsal fins have been reported most frequently in killer whales (Bigg et al. 1987, Baird and Stacey 1989, Visser 1998). Killer whales are highly sexually dimorphic, and the dorsal fin of an adult male is approximately twice the height of the dorsal fin of an adult female. All cases of collapsed fins in killer whales have been adult males, and presumably the high frequency of such disfigurements for this species is related to the unusually large fin. In Prince William Sound, Alaska, collapsed dorsal fins have been documented for three adult males (Matkin et al. 1999), two of which had their fins collapse shortly after exposure to oil from the Exxon Valdez spill, sug- 


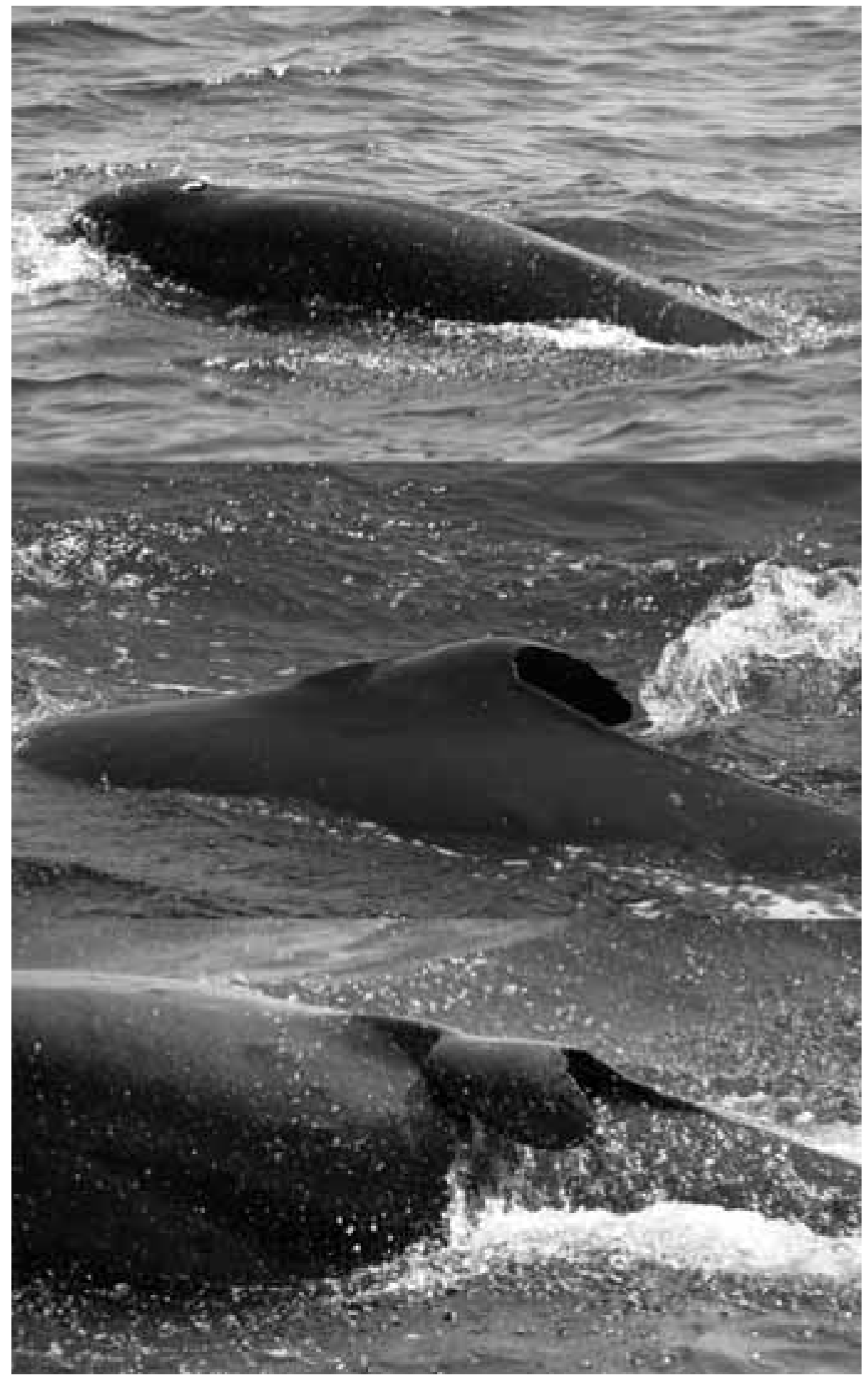

FIGURE 1. (Top) False killer whale (catalog no. HIPc177) with missing dorsal fin. (Middle) False killer whale (catalog no. HIPc166) with dorsal fin bent over to right with injury at base of leading edge of fin. (Bottom) False killer whale (catalog no. HIPc186) with dorsal fin bent over to left with injury at base of leading edge of fin. 
gesting that dorsal fin collapse may be related in some cases to poor health or stress (Matkin et al. 1999). Visser (1998) reported one adult male killer whale with a collapsed fin and with an indentation around the thorax, suggesting that the individual may have been entangled at some time.

For Hawaiian false killer whales, the most likely causes of the disfigurements we have documented include sharks, boat strikes, or fishing gear entanglements. Shark bite wounds are typically jagged, and dorsal fin injuries from sharks appear to be relatively uncommon, compared with injuries on other parts of the body (Heithaus 2001). Depending on propeller size, boat strike wounds can be somewhat linear (e.g., Wells and Scott 1997, Visser and Fertl 2000), though examples of odontocetes with recognized boat strike wounds involving the dorsal fin consist of a series of vertical cuts through the fin and/ or along the body adjacent to the fin, unlike the injuries we observed. It thus seems unlikely that the disfigurements we have documented resulted from shark bites or boat strikes.

Observer reports from the Hawaili long-line fishery have noted that false killer whales struggle vigorously when hooked (E. Forney, pers. comm.), and a photograph of one hooked false killer whale from this fishery shows a linear mark extending posteriorly from the mouth along the side of body (Figure 2), presumably an abrasion from struggling against the longline. All three of the animals we documented with completely or partially bent-over fins had injuries at the leading edge base of the fin. Such injuries are consistent with line or fishing gear injuries documented from other cetaceans (see, e.g., Norris 1992, Wells et al. 1998, Robbins and Mattila 2001). We suggest that the major dorsal fin disfigurements we have documented from Hawaici false killer whales are most likely a result of long-line interactions such as this, with an animal struggling against a longline rolling against the gear and injuring or severing the dorsal fin in such struggles. Injuries at the base of the leading edge of the fin could result in dorsal fin collapse either through loss of structural support (be- cause the fin is thickest at the anterior end) or through heating of the fin during healing, resulting in softening of the collagen and subsequent bending of the fin ( $\mathrm{J}$. McBain, pers. comm.). For the animal missing the fin, a line wrapped at the base of the dorsal fin could work its way through the fin slowly, as was documented for a spinner dolphin in Hawaiian waters (Green et al. 1991; see also Norris 1992). It is possible that the missing dorsal fin is simply a congenital defect; however the presence of scar material at the site of the missing fin suggests that this is unlikely. Such disfigurements suggest that false killer whales seen around the main Hawaiian Islands are part of the same population that interacts with long-line fisheries in areas at least $80 \mathrm{~km}$ from shore. It is also possible that such disfigurements may have come from interactions with other Hawaiian fisheries, such as the nearshore commercial or sports troll fishery, although there is no information available to assess the likelihood of this possibility.

Few published data are available on rates of such major dorsal fin disfigurements from other populations of odontocetes, though we were able to compile unpublished data from a number of researchers (Table 1). The rate of major dorsal fin disfigurements in our study is more than four times higher than for any other population of odontocete that we were able to find data on. Of the 14 studies (including ours), our total number of marked individuals ranks 13 th, yet our number of individuals with major disfigurements is tied for first rank. Although survey methods may vary between studies, individuals with missing or bent-over fins are quite unusual and are likely to have been noted if seen (personal communications from sources in Table 1). Some of the populations in Table 1 are known to interact with fisheries (e.g., North Carolina Tursiops [Friedlaender et al. 2001]; New Zealand Orcinus [Visser 2000]), though it is possible that lower rates of dorsal fin injuries may be due to higher rates of mortality per interaction, differences in gear type used (e.g., gill nets versus longlines), or species differences in how animals respond to hooking or entanglement. 


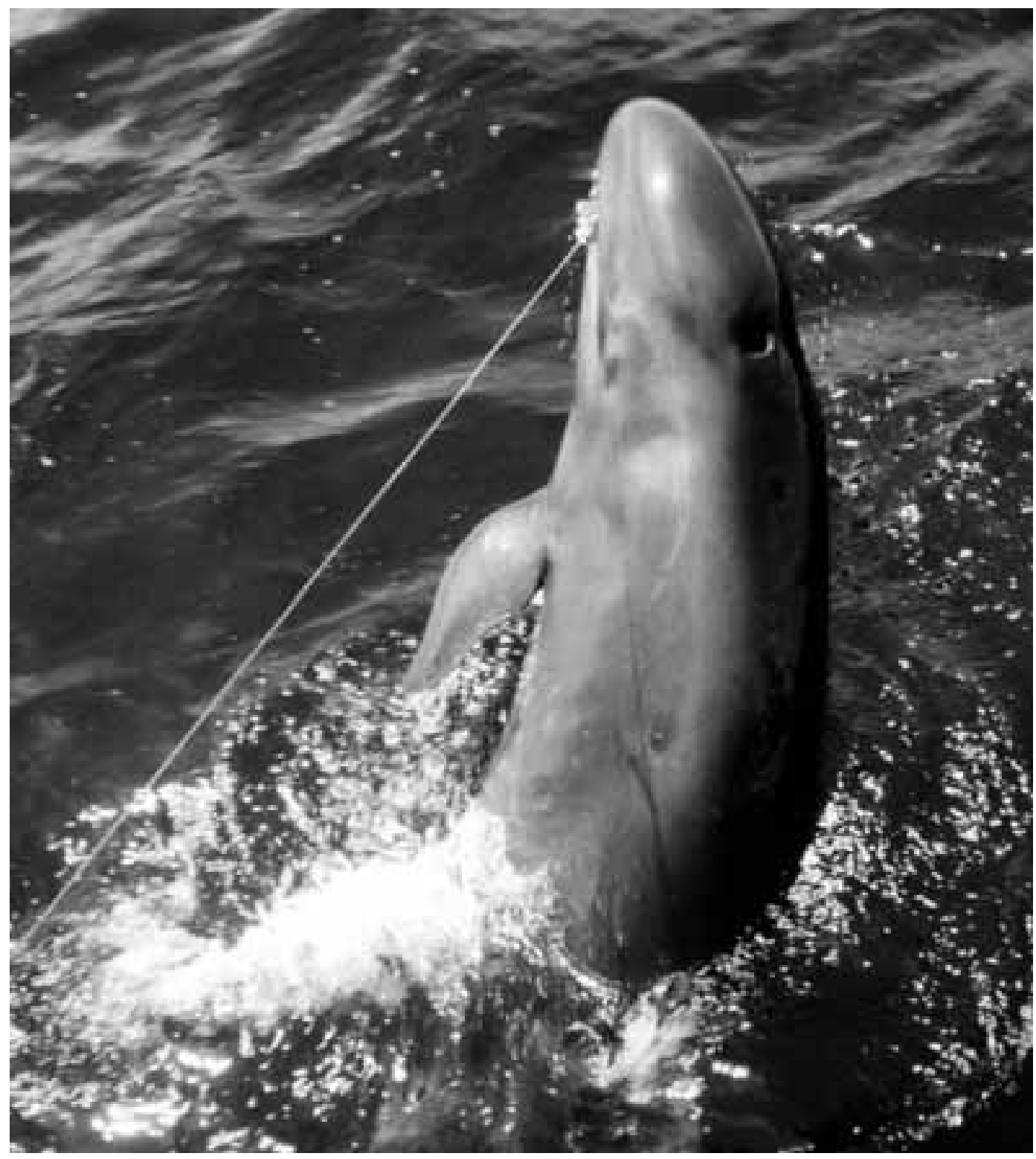

FIgURE 2. Hooked false killer whale from the Hawai'i long-line fishery, showing linear mark along side of body apparently as a result of long-line abrasion. Examination of a high-resolution scan of the original photo shows that the mark is not equally dark along the irregular surface of the body, and it clearly extends into the shadowed area of the back, indicating that the mark is not a shadow from the longline. Photo by Eric Forney, courtesy NOAA Fisheries, Pacific Islands Region.

Our results also have implications regarding the ability of seriously injured animals to survive and reproduce. The dorsal fin is known to be of importance in thermoregu- lation, providing cooled blood to the female reproductive system (Rommel et al. 1993). Two of the individuals with disfigurements were thought to be adult females and both 


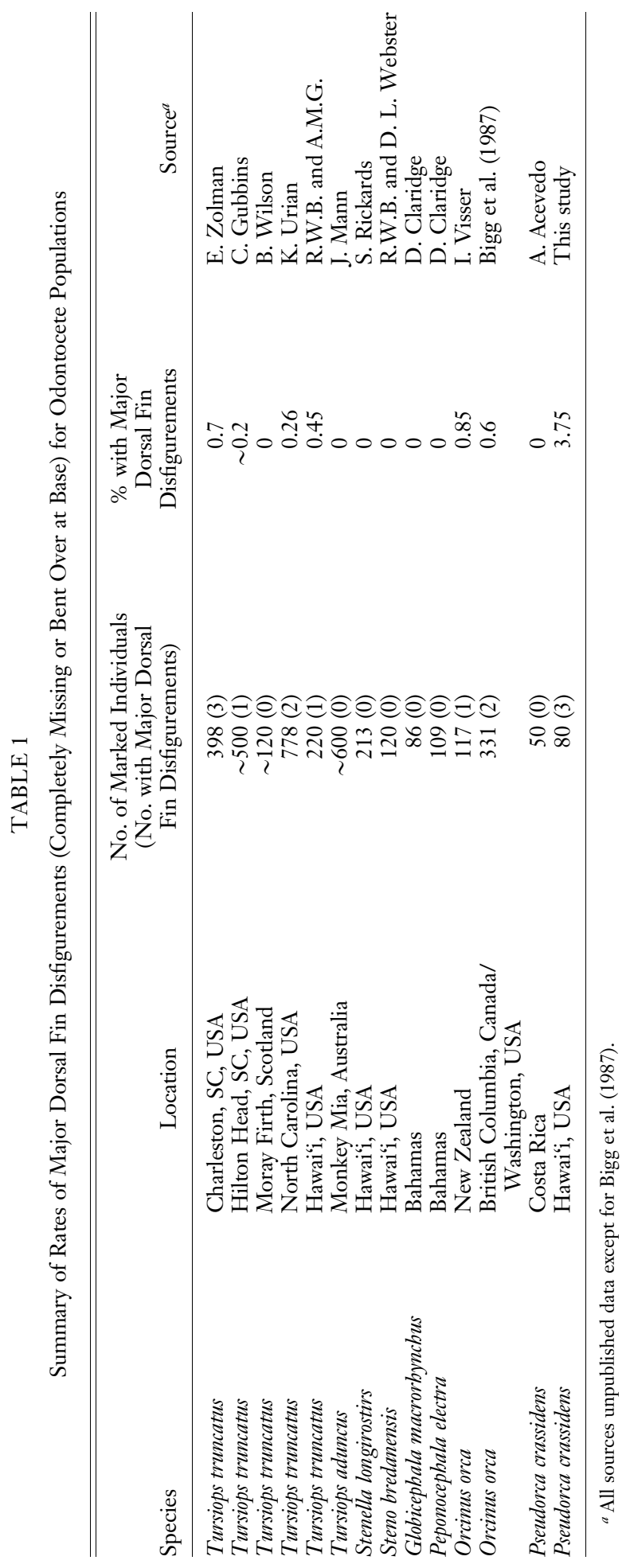


were accompanied by infants estimated to be less than a year of age. Our observations of an individual completely missing the dorsal fin accompanied by an infant implies that even with such major losses, adult females may be able to adequately thermoregulate and reproduce, at least in some cases.

\section{ACKNOWLEDGMENTS}

Allan Ligon, Dan McSweeney, and Daniel Webster all provided substantial assistance in the field efforts. Research vessels were provided by Island Marine Institute, Joe Mobley (University of Hawai'i), and the Wild Whale Research Foundation. Bill Gilmartin and Hannah Bernard from the Hawai'i Wildlife Fund administered much of the funding. We thank Alejandro Acevedo, Diane Claridge, Cara Gubbins, Janet Mann, Susan Rickards, Kim Urian, Ingrid Visser, Ben Wilson, and Eric Zolman for providing unpublished information, and Kevin Busschler and Lesley Jantz of the National Marine Fisheries Service, $\mathrm{Pa}-$ cific Islands Region, for providing a photograph from the observer program for the Hawai'i-based long-line fishery. Discussions with Jim McBain regarding wound healing were very helpful. Bud Antonelis, Jason Baker, Barbie Byrd, Karin Forney, Brad Hanson, Bill McLellan, Joe Mobley, Ingrid Visser, and an anonymous reviewer all provided constructive comments on various versions of the manuscript.

\section{Literature Cited}

Baird, R. W., and P. J. Stacey. 1989. Observations on the reactions of sea lions, Zalophus californianus and Eumetopias jubatus, to killer whales, Orcinus orca, evidence of "prey" having a "search image" for predators. Can. Field-Nat. 103:426-428.

Baird, R. W., P. J. Stacey, D. A. Duffus, and K. M. Langelier. 2002. An evaluation of gray whale (Eschrichtius robustus) mortality incidental to fishing operations in British Columbia, Canada. J. Cetacean Res. Manage. 4:289-296.

Barlow, J. 2003. Cetacean abundance in Hawaiian waters during summer/fall of 2002 .
National Marine Fisheries Service Southwest Fisheries Science Center Administrative Report LJ-03-13.

Bigg, M. A. 1982. An assessment of killer whale (Orcinus orca) stocks off Vancouver Island, British Columbia. Rep. Int. Whaling Comm. 32:655-666.

Bigg, M. A., G. M. Ellis, J. K. B. Ford, and K. C. Balcomb. 1987. Killer whales: A study of their identification, genealogy, and natural history in British Columbia and Washington State. Phantom Press, Nanaimo, British Columbia, Canada.

Carretta, J. V., K. A. Forney, M. M. Muto, J. Barlow, J. Baker, and M. Lowry. 2004. U.S. Pacific marine mammal stock assessments: 2003. NOAA Tech. Memo. NMFS-SWFSC 358.

Chivers, S. J., R. G. LeDuc, and R. W. Baird. 2003. Hawaiian island populations of false killer whales and short-finned pilot whales revealed by genetic analyses. Page 32 in Abstracts of the 15th Biennial Conference on the Biology of Marine Mammals, 1419 December 2003, Greensboro, North Carolina.

Chu, K., and S. Nieukirk. 1988. Dorsal fin scars as indicators of age, sex, and social status in humpback whales (Megaptera novaeangliae). Can. J. Zool. 66:416-420.

Corkeron, P. J., R. J. Morris, and M. M. Bryden. 1987. Interactions between bottlenose dolphins and sharks in Moreton Bay, Queensland. Aquat. Mamm. 13:109-113.

Friedlaender, A. S., W. A. McLellan, and D. A. Pabst. 2001. Characterising an interaction between coastal bottlenose dolphins (Tursiops truncatus) and the spot gillnet fishery in southeastern North Carolina, USA. J. Cetacean Res. Manage. 3:293303.

Green, H. C., J. Ostman, and A. D. Driscoll. 1991. A case of dolphin entanglement leading to a portion of the fin being cut off-how "round nick" became "butch". Page 29 in Abstracts of the Ninth Biennial Conference on the Biology of Marine Mammals, 5-9 December 1991, Chicago, Illinois.

Heithaus, M. R. 2001. Shark attacks on bottlenose dolphins (Tursiops aduncus) in 
Shark Bay, Western Australia: Attack rate, bite scar frequencies and attack seasonality. Mar. Mamm. Sci. 17:526-539.

Hillman, G. R., B. Würsig, G. A. Gailey, N. Kehtarnavaz, A. Drobyshevsky, B. N. Araabi, H. D. Tagare, and D. W. Weller. 2003. Computer-assisted photoidentification of individual marine vertebrates: A multi-species system. Aquat. Mamm. 29:117-123.

Jefferson, T. A., B. C. Curry, and N. A. Black. 1994. Harbor porpoise mortality in the Monterey Bay halibut gillnet fishery, 1989. Rep. Int. Whaling Comm. Spec. Issue 15:445-448.

Knowlton, A. R., and S. D. Kraus. 2001. Mortality and serious injury of northern right whales (Eubalaena glacialis) in the western North Atlantic Ocean. J. Cetacean Res. Manage. Spec. Issue 2:193-208.

Mann, J., R. A. Smolker, and B. B. Smuts. 1995. Responses to calf entanglement in free-ranging bottlenose dolphins. Mar. Mamm. Sci. 11:100-106.

Matkin, C., G. Ellis, E. Saulitis, L. BarrettLennard, and D. Matkin. 1999. Killer whales of southern Alaska. North Gulf Oceanic Society, Homer, Alaska.

Mobley, J. R., S. S. Spitz, K. A. Forney, R. A. Grotefendt, and P. H. Forestell. 2000. Distribution and abundance of odontocete species in Hawaiian waters: Preliminary results of 1993-98 aerial surveys. National Marine Fisheries Service Southwest Fisheries Science Center Administrative Report LJ-00-14C.

Nitta, E. T., and J. R. Henderson. 1993. A review of interactions between Hawaii's fisheries and protected species. Mar. Fish. Rev. 55:83-92.

Norris, K. S. 1992. Dolphins in crisis. Natl. Geogr. 182 (3): 2-35.

Read, A. J., P. Drinker, and S. Northridge. 2003. By-catches of marine mammals in U.S. fisheries and a first attempt to estimate the magnitude of global marine mammal by-catch. Document SC/55/BC presented to the International Whaling Commission Scientific Committee.

Robbins, J., and D. K. Mattila. 2001. Monitoring entanglements of humpback whale (Megaptera novaeangliae) in the Gulf of Maine on the basis of caudal peduncle scarring. Document SC/53/NAH25 presented to the International Whaling Commission Scientific Committee.

Rommel, S. A., D. A. Pabst, and W. A. McLellan. 1993. Functional-morphology of the vascular plexuses associated with the cetacean uterus. Anat. Rec. 237:538546.

Scott, M. D., R. S. Wells, A. B. Irvine, and B. R. Mate. 1990. Tagging and marking studies on small cetaceans. Pages 489-513 in S. Leatherwood and R. R. Reeves, eds. The bottlenose dolphin. Academic Press, New York.

Visser, I. N. 1998. Prolific body scars and collapsing dorsal fins on killer whales $(\mathrm{Or}$ cinus orca) in New Zealand waters. Aquat. Mamm. 24:71-78.

. 2000. Killer whale (Orcinus orca) interactions with longlines fisheries in New Zealand waters. Aquat. Mamm. 26:241252.

Visser, I. N., and D. Fertl. 2000. Stranding, resighting, and boat strike of a killer whale (Orcinus orca) off New Zealand. Aquat. Mamm. 26:232-240.

Wells, R. S., and M. D. Scott. 1997. Seasonal incidence of boat strikes on bottlenose dolphins near Sarasota, Florida. Mar. Mamm. Sci. 13:475-480.

Wells, R. S., S. Hofmann, and T. L. Moors. 1998. Entanglement and mortality of bottlenose dolphins, Tursiops truncatus, in recreational fishing gear in Florida. Fish. Bull. 96:647-650. 
